\title{
Making community based comprehensive mental health services work
}

\author{
Karen White, Maresa Ness, Tom Craig and Gary McNamee
}

\begin{abstract}
There has been unill recently a deatth of descriptions of locelly torgeted community mental hectth services. such a service, doveloped by changing a traditional poychiatilic service in an inner selting, is described. The service oddreseses the needs of those with predominantly sovere/enduring mental health problems, by increadingty uing resecurch based trociments in on ordinary atifict sotting.
\end{abstract}

Providers of mental health services are subject to increasing demand from purchasers, patients, carers, politiclans and pundits, to provide workable alternatives to the large mental hospitals. Descriptions of isolated service components, such as the acute day programme (Creed et al, 1989) and assertive case management (Muijen et al, 1992) exist in the literature but as Hoult (1993) states there are few descriptions of comprehenstve systems of care. This paper seeks to outline the system of care adopted in a sectorised inner city provider unit (West Lambeth Community Care (NHS) Trust), which lays a firm foundation for the provision of a comprehensive service to those with mental health problems in a difficult inner city area. This service is based at the Lewin Road Community Mental Health Centre in Streatham.

\section{Background}

Until the late 1980s, psychiatric care in West Lambeth was almost entirely based on the inpatient and out-patient provision of three separate hospitals (St Thomas', the South Western and Tooting Bec). Consultant psychiatrists looked after the psychiatric needs of catchment areas in excess of $\mathbf{4 0 0 0 0}$ adults and the service entirely revolved around in-patient, out-patient and day hospital care. A somewhat token gesture towards community based services was provided by a community nursing service which was under-resourced and over-stretched by a combination of excesstve demand for counselling interventions from primary care and large caseloads of chronic patients on static maintenance programmes. A follow-up study of patients diagnosed as suffering from schizophrenia demonstrated clearly that the then current services were simply not providing appropriate care for the needs of these patients even as soon as a year after discharge from hospital, with over half the cohort suffering inadequately treated psychotic symptoms (Meltzer et al, 1991).

The need for more effective community services had been recognised from at least the mid-1980s and planning documents of the time were quite clear about just what was required - sectorisation of the district (with a more rational allocation of catchment areas), the development of skilled multidisciplinary teams and the provision of accessible community bases for these teams. But progress towards achieving these goals has been slow and far more difficult than anyone anticipated when the plans were first drawn up. The process began with the launch of a community mental health centre in Streatham ('Gable House') which almost immediately foundered in the face of opposition from consultant medical staff. Lacking senior psychiatric input, the centre dealt mainly with neurotic and stress-related conditions and made little contribution to the care of severely mentally ill people in the district. Consequently, in 1989 as part of an effort to refocus the Centre on the needs of severely mentally ill people, the Day Hospital at Tooting Bec Hospital was relocated to the Gable House site and shortly thereafter a community psychiatric nurse team was also relocated. Although well intentioned, and this time supported by senior psychiatric involvement, too little attention was given to integrating the three staff teams or to tackling their relationship to in-patient care. Not surprisingly, despite physical relocation, the services continued to operate almost entirely independently of each other, each with its separate identity, function and method of working. Clients often faced multiple assessments as they moved between in-patient and community care or even between different arms of the community services. Resources were ill defined and untargeted, staff were confused and 
demoralised and referrers bemused by the multplicity of access points to the service.

\section{The Lewin Road Centre}

In the face of this confusion, the trust took the strategic decision to concentrate resources largely on clients with severe/enduring mental health problems to simplify access to services, to introduce standardised assessment procedures and a more focused 'problem-centred' general approach to care delivery. All staff at the centre would be provided with training in standardised methods of assessment and then reorganised to provide three core services: a team providing time-limited goal-directed therapies, an assertive community treatment case management team for people suffering from severe/persistent mental illness, and a crisis assessment and treatment service. The re-shaped service and the vision of the service model was communicated to the entire staff during a one-day meeting which included the participation of all the sector consultants as well as the Director of Mental Health and his management team. Staff agreed to pilot the new service models for three months, to evaluate the new way of working and to report back at the end of a three month period.

The same plan was then outlined to stakeholders at open evenings in the presence of Chairman, Chief Executtve and entire staff team again. Purchasers (one major purchaser), general practitioners (GPs), social services, voluntary sector agencies, users of services and carers were all invited and heard about the three month pilot and were invited to give feedback.

Following the pilot and having signed up the stakeholders, a full programme of change was initiated. Given the complexity of change and the previous failure of piecemeal amendments, it was decided to institute a major change programme. This involved issuing statutory notices of risk of redundancy to all staff, the re-writing of job descriptions to specify precisely new roles and duties, and a full programme of consultation with all staff and their representative bodies.

The re-configured service provides mental health care to adults aged 16-65 years. The population of the Southern Sector is 66000 with $27 \%$ coming from ethnic minority groups and a Jarman index of 8 . The hospital in-patient unit consistently has a bed occupancy rate of over $100 \%$ with at least $50 \%$ detained under the Mental Health Act 1983.

\section{Assessment and treatment team}

The assessment and treatment team provides the gateway into the service, it offers assessment of all non-urgent and urgent referrals, working closely with local GPs and social services to provide treatment 'packages' based on individual need. These care packages are agreed in a consultant-led multidisciplinary team meeting and a management plan formulated following discussion with the client. The team offers treatment using time-limited goal directed therapies, often in a group setting, with evaluation of outcome.

Services include:

- Family work including psycho-education interventions for patients with a diagnosis of schizophrenia (Leff et al, 1982).

- Alliance/compliance enhancing interventions which include:

(a) groups - to faclitiate medication monitoring and discussion, engaging service users as co-therapists in managing symptoms, side effects and compliance. These clients do not attend formal out-patient clinics and are able to negotlate changes in medication within the group. They are supplied with prescriptions and depots locally

(b) individual focus on monitoring of early signs of relapse and early intervention targeted at clients who find group work difficult (Macmillan et al, 1992)

(c) cognittive analytical therapy

(d) general psychotherapy groups

(e) cognitive-behavioural interventions for affective and other disorders

(f) psychological counselling

(g) adult education classes in art and drama as well as leisure groups using local facilities

(h) a weekly users' forum is open to all clients and at the users' request is attended by the service manager and clinical staff

(i) in addition the team supports a 'Link' group to support individuals facing discharge from the in-patient unit

(j) members of Phobic Action self-help group meet weekly.

\section{A case management team}

This was established to ensure discrete, guaranteed services to persons known to have severe and enduring mental health problems who have not engaged with another part of the service, and who are vulnerable to multiple hospital admissions. Based on team rather than individual working and offering extended hours and days of the week, the service broadly matches the recommendations of the recent Ritchie et al report (1994) by providing continuing care for 105 clients who meet at least two of the following criterla: 
(a) a history of having been detained in hospital under the Mental Health Act 1983 on more than one occasion

(b) a history of violence or persistent offending

(c) failure to respond to treatment from the general psychiatric services

(d) a history of severe or repeated attempts at self-harm.

Members of this team act as key-workers for clients accepted on the Care Programme Register, attending pre-discharge conferences on the inpatient units and convening regular reviews in the community. This team offers assertive outreach and case management interventions based on the model developed in Wisconsin, USA until the client is able to move into another part of the service.

Each case manager carries a total case load of 17 to 18 clients, to allow the team to offer extended hours working and assertive and where necessary intensive input. The team also utilises the skdlls of the assessment and treatment team for specific treatment activities.

Allied to this team are three outreach nurses who support approximately 30 individuals with long-term needs, but who do not require such intensive treatment or follow-up, e.g. clients who are not reliable in attending for medication or review, but who will cooperate with home visits and whose mental states are fairly stable. There is recognised movement between case management and outreach allowing flexibility in intensity of support.

Links to in-patient services are a particularly important aspect of case management and outreach activity. In addition to keyworker roles through the Care Programme Approach, case managers regularly work with their clients during admission to hospital. Nurses on the in-patient team also rotate to the case management team as a regular cycle thus reducing the barrier between in-patient and community care.

\section{Crisis service}

All service staff work together to provide a sameday assessment of crisis referrals, providing two staff to make assessments either at the centre or elsewhere. Section 12 approved medical backup is always available. Referrals are recetved mainly from GPs and local social services departments although referrals by clients and carers are accepted. Following assessment, the members of the team have the facility to admit patients direct to the in-patient unit if deemed necessary. Clients can be supported on a daily basis either at the centre or at home, prescribed medication if appropriate and assessed for further interventions by the assessment and treatment team. The crisis role continues with the client for up to two weeks or until crisis resolution, before decisions regarding further long-term care or other disposal are made through the assessment and treatment team.

\section{Out of hours helpline}

Staffed by all clinical staff in both sectors, an out of hours helpline exists to support clients currently engaged with case management and outreach services in the Trust. It offers telephone guidance on issues of medication compliance and use, management of anxiety, side effects and other difficulties likely to face service users out of hours.

\section{The role of the poychiatrist}

In addition to sessional inputs from sector consultants, there are two permanent non-training grade, section 12 approved psychiatrists. This staffing enables rapid access to section 12 approved doctors in an emergency and ensures that all patients suffering from psychoses and other severe and persistent mental illness are supervised in the long-term by an experienced senior psychiatrist. In order to boost the competence of the team, one of these staff doctors was encouraged to develop a special interest in the pharmacological management of major mental illness and a training package was provided which included secondment to specialist services elsewhere in London. The other staff psychiatrist has had a similar training and supervision in a range of psychological interventions.

Consultant psychiatrists have played a lead role in designing and shaping the services, in supervising care delivery and providing training for the multidisciplinary team in the assessment of mental state, suicide risk and dangerous behaviour. They are directly involved in the formulation of the care plan of all cases managed at the centre. All newly-referred cases are discussed following assessment, with one of the two sector consultants and all cases with histories of admission to hospital or psychotic disorder are regularly reviewed by the consultant.

Opportunities within this change have included close collaboration with social services and the housing department who run a special needs housing clinic from the centre, and have also jointly provided an Asian mental health service and Clubhouse facility (Beard et al, 1992). The services have developed close working links with day care providers including the voluntary sector, rehabilitation services within health and social services and a range of other agencies. 


\section{Managing the change}

The challenge to staff who participated in this change was always recognised. The mechanisms of support included frequent consultative meetings with senior management and lead clinicians. An independently facilitated staff group was established to faclititate resolution of staff difficulties. Internal leadership was established through the setting up of a defined management structure. A rolling programme of secondments/ placements of hospital staff into the community was established to ensure enhanced joint working between hospital and community services, as well as joint facilitation of the 'Link' group.

Despite a difficult and complex period of change the service has now bedded down and enjoys positive relationships with its stakeholders. The total caseload is approaching $\mathbf{4 0 0}$ and the model is now being replicated in the newly opened Mental Health Centre in the Northern Sector and will continue to influence any future community development within the Trust. The changes have been fully accepted and welcomed by all stakeholders, particularly colleagues in general practice.

\section{References}

Beard. J., Propst, R. \& Malamud, T. (1982) The Fountain House model of poychiatric rehabilitation. Psycho-soctal Rehabiltation Journal, 6. 47-53.

Creed, F. H., ANTHONY, P., GodBert. K., et al (1989) Treatment of severe psychlatric illness in a day hospital. Brttish Journal of Psychiatry, 164, 341-347.
HoLT, J. (1993) Comprehenstve services for the mentally ill. Current Optrion in Psychiatry, 6, 238-245.

LEPT, J., KUIPERS, L., BERKOWITZ, R., et al (1982) A controlled trial of social intervention in the families of schizophrenics. British Journal of Psychiatry. 141. 121-134.

Macmmun, F., Brichwood, M. \& SMTrH, J. (1992) Predicting and controlling relapse in schizophrenia: early signs monitoring. In Schirophrenia: an overview and practical handbook (ed. D. Kavanagh). London: Chapman \& Hall.

MeltZer, D., HALE, A. S., MALK, S. J., et al (1991) Community care for patients with schizophrenia one year after hospital discharge. British Medical Journal. sos, 1023-1026.

MuLJen, M., MARKS, I. M., Connouly, J., et al (1992) The Dally Ltving Programme. Preliminary comparison of community versus hospital based treatment for the seriously mentally ill facing emergency admission. Brittsh Journal of Psychiatry. 160, 379-384.

RircHIE, J. H., Dick, D. \& LNGHAM, R. (1994) The Report of the Inquiry into the Care and Treatment of Christopher Clunis. London: HMSO.

*Karen White, Consultant in Community Psychiatry, Folkestone Community Mental Health Centre, 8 Radnor Park Avenue, Folkestone, Kent CT19 5BW; Maresa Ness, Service Manager, Lewin Road, Community Mental Health Centre, West Lambeth Community Care (NHS) Trust, 55 Lewin Road, London SWI6 6JZ; Tom Craig, Professor of Community Psychiatry, UMDS, St Thomas' Hospital, London SE1; and Gary McNamee, Senior Manager, South Western Hospital, Pulross Road, London SW9

*Correspondence 